\title{
Anomalous origin and vulnerable course of left colic artery in relation to the pancreas-A case report
}

\author{
Satheesha Badagabettu Nayak*, Surekha Devadasa Shetty, Srinivasa Rao Sirasanagandla, \\ Ashwini Aithal, Swamy Ravindra Shanthakumar
}

Melaka Manipal Medical College (Manipal Campus), Manipal University, Manipal, India;

*Corresponding Author: nayaksathish@gmail.com

Received 24 May 2013; revised 16 July 2013; accepted 25 July 2013

Copyright (C) 2013 Satheesha Badagabettu Nayak et al. This is an open access article distributed under the Creative Commons Attribution License, which permits unrestricted use, distribution, and reproduction in any medium, provided the original work is properly cited.

\begin{abstract}
We report here an anomalous origin and course of left colic artery in relation to pancreas during routine dissection of the abdominal region in a 70-year-old male cadaver in the department of anatomy. The anomalous left colic artery took its origin from the superior mesenteric artery and immediately divided into right and left branches. The right branch passed through the transverse mesocolon to supply the left one third of the transverse colon. The left branch traversed to the left along the inferior border of the body of the pancreas and crossed the left kidney before supplying the left colic flexure of colon and descending colon. This aberrant course of the left branch of the left colic artery can be considered as a "vulnerable" course as it is liable to injury during pancreatic and renal surgeries since the artery is not expected to run along the inferior border of the pancreas. The pancreas, a retroperitoneal organ, is related to major arteries such as abdominal aorta, inferior vena cava, coeliac trunk and its main branches, superior mesenteric vessels, splenic and portal veins. Surgery of the pancreas therefore, not only needs a thorough knowledge of the normal course of branches of these vessels but also demands a good knowledge of possible anomalous vessels arising in this region.
\end{abstract}

Keywords: Left Colic Artery; Pancreas; Inferior Mesenteric Artery; Superior Mesenteric Artery

\section{INTRODUCTION}

The abdominal aorta gives three ventral branches, namely the celiac trunk, the superior mesenteric artery and the inferior mesenteric artery. The celiac trunk supplies the derivatives of the foregut; the superior mesenteric artery supplies the derivatives of the midgut and the inferior mesenteric artery supplies the derivatives of the hindgut. Normally, the left colic artery is the first branch of inferior mesenteric artery. It ascends retroperitoneally and divides into ascending and descending branches. The ascending branch passes anterior to the left kidney and supplies the left one third of the transverse colon and the upper part of the descending colon, whereas the descending branch supplies the lower part of the descending colon [1].

The normal course of the left colic artery is not closely related to the pancreas. The pancreas, as we know, is a mixed gland, which is partly exocrine and partly endocrine in function. It is a soft lobulated, retroperitoneal gland that extends from the C-loop of duodenum to the splenic hilum, obliquely across the vertebral column. It is closely related to the abdominal aorta, inferior vena cava, coeliac trunk and its branches, superior mesenteric vessels, splenic and portal veins. Pancreatic surgery, in particular the pancreaticoduodenectomy is considered to be a formidable surgery [2]. In 1960s, its postoperative morbidity rate was $60 \%$ and mortality rate was about $25 \%$ [3]. However, with the advance of technology, at present the mortality rate has come below $5 \%$ but the morbidity rate is still around $30 \%$ to $60 \%$ [3-5]. Postoperative bleeding occurs in $3 \%-13 \%$ of patients after pancreatic surgery $[4,6,7]$.

Here we present a case of the anomalous origin and course of left colic artery and discuss its clinical importance.

\section{CASE REPORT}

We found a rare variation in the branching pattern of superior mesenteric artery. Anomalous origin, course, distribution and termination of the left colic artery were 
observed in an adult male cadaver of South Indian origin, aged 70 years, during routine dissection by medical undergraduates in the department of anatomy, Melaka Manipal Medical College, Karnataka. The anomalous left colic artery originated from the superior mesenteric artery and divided into left and right branches immediately (Figure 1). The level of origin of the artery was situated just below the body of the pancreas, arising from the right side of superior mesenteric artery. The right branch passed through the transverse mesocolon and supplied the left one third of the transverse colon. The left branch coursed to the left, first along the inferior border of the body of pancreas and then anterior to the left kidney (Figures 1 and 2).

After crossing the left kidney, it divided into ascending and descending branches which supplied the left colic flexure of colon and the descending colon, respectively. The middle colic and right colic arteries arose through a common trunk from the superior mesenteric artery. The other branches of the superior mesenteric artery, namely the inferior pancreaticoduodenal, jejunal, ileal and ileocolic arteries had normal course and distribution. The inferior mesenteric artery gave only sigmoidal branches and continued down as the superior rectal artery (Figure 2). Thus the inferior mesenteric artery had a minor contribution to the formation of Marginal Artery of Drummond.

\section{DISCUSSION}

The abdominal aorta gives rise to three ventral splanchnic branches, namely the celiac trunk, the superior mesenteric artery and the inferior mesenteric artery,

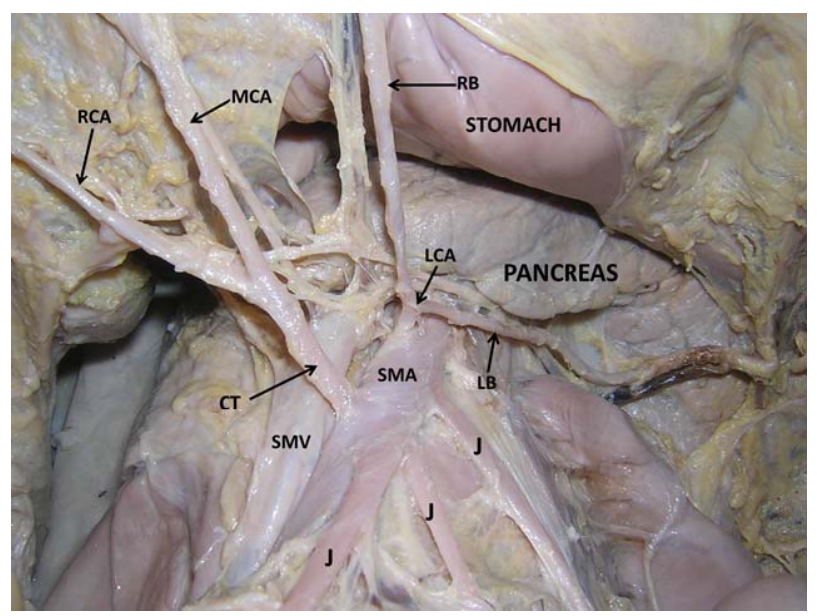

Figure 1. Dissection of the abdomen showing the anomalous origin of the left colic artery. (SMA - superior mesenteric artery; LCA — left colic artery; RB — right branch of left colic artery; LB — left branch of left colic artery; CT_common trunk of origin of right and middle colic arteries; RCA—right colic artery; MCA — middle colic artery; SMV—-superior mesenteric vein; J-jejunal branches of superior mesernteric artery).

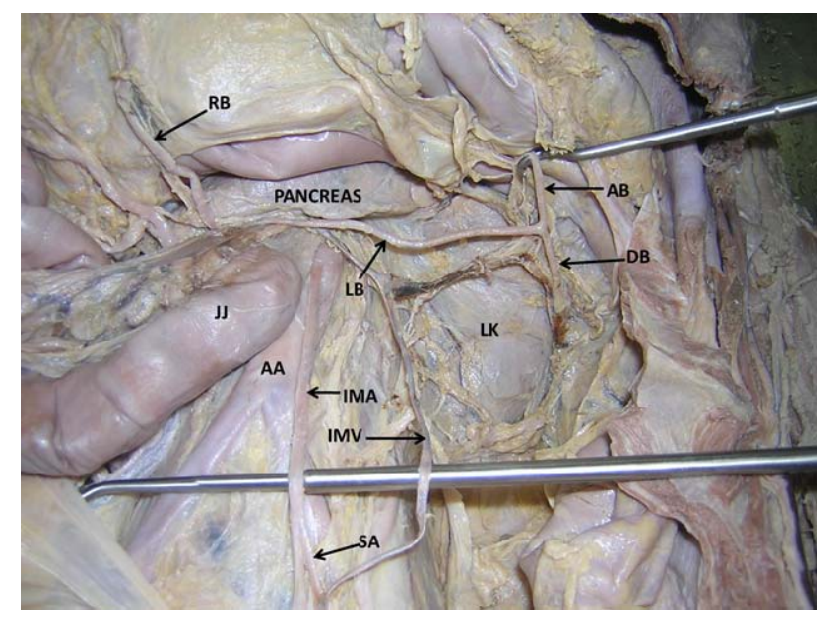

Figure 2. Dissection of the abdomen showing the dangerous course of the left branch of the left colic artery. (LB-left branch of left colic artery; RB —right branch of left colic artery; DB - descending branch of the left branch of left colic artery; $\mathrm{AB}$ - ascending branch of the left branch of left colic artery; AA—abdominal aorta; IMA — inferior mesenteric artery; IMVinferior mesenteric vein; LK—left kidney; JJ—jejunum; SAsigmoidal artery).

which supply the derivatives of the foregut, midgut and hindgut respectively [1]. The variation in the number and branching pattern of the arteries of the gut may be correlated with their embryologic development. During the early fetal life, the two dorsal aortae, before the stage of their fusion, give ventral splanchnic branches which supply the gut and its derivatives. In the beginning, the ventral branches are paired. But when the dorsal aortae fuse, these ventral branches fuse and form a series of unpaired segmental arteries. These arteries run in the dorsal mesentery of the gut and are divided into ascending and descending branches. These arteries ultimately form dorsal and ventral longitudinal anastomotic channels. After the formation of longitudinal anastomotic channels, numerous ventral splanchnic branches disappear and only three trunks persist as the celiac trunk, the superior mesenteric artery and the inferior mesenteric artery [8]. Any deviation from the normal pattern of fusion of these channels can lead to the existence of anomalous branching pattern of these major vessels.

Superior and inferior mesenteric arteries are known to show variations in its branching pattern. A study reports the origin of an accessory right hepatic artery from the superior mesenteric artery [9]. Anomalous origin of the hepatic artery from the hepatomesenteric trunk has also been reported [10]. In a study conducted by Ashwini et al., (2013), the right colic artery was absent in $10 \%$ of cases and in $34 \%$ of cases, it arose as a common trunk with the middle colic artery [11]. The origin of splenic artery from superior mesenteric artery and the appendicular artery from the right colic artery have been re- 
ported very recently [12]. In a study by Simeon et al., (2013) on fifty seven formalin embedded cadavers, the inferior mesenteric artery branched into left colic artery and a common sigmoid trunk in twenty three cases, while the classical branching pattern was observed in only seven cases [13].

Variations of the left colic artery are however, extremely rare. Though there are a few reports on its variations, there is no report on its close relation with the inferior border of the body of the pancreas, as seen in the present case study. Rusu et al., (2008) have reported the presence of an aberrant accessory left colic artery [14]. It originated from the superior mesenteric artery about 3 $\mathrm{cm}$ proximal to the middle colic artery, near the inferior border of pancreas. It reached the colon by passing over the Treitz's muscle. Jiji P. J. et al., (2008) observed a case of anastomosis between the left colic artery and dorsal pancreatic artery [15]. Origin of the left colic artery as a branch of celiaco-mesenteric trunk has also been reported recently [16]. In the present case study, we observed that the superior mesenteric artery was an independent branch of the abdominal aorta and it gave rise to the left colic artery. Origin of the left colic artery from superior mesenteric artery is seen in less than $1 \%$ of cases. Kim et al., (2009) have reported such a case from Korea [17]. The current case is somewhat similar to this case.

Developmentally, the branches of the superior mesenteric artery supply the derivatives of the midgut and the branches of the inferior mesenteric artery supply the derivatives of the hindgut [18]. In the current case, it is difficult to explain why a branch of the artery of the midgut is supplying the derivatives of the hindgut. The left colic artery being reported in the current case draws special attention to not only its origin and distribution, but also to its close relation to the pancreas. The course of the left branch of the left colic artery is quite unusual. Its relationship with the lower border of the pancreas may make it vulnerable during pancreatic surgeries since the surgeons normally do not expect an artery of that caliber in the vicinity.

The gastroenterologists and radiologists while formulating the treatment plan and performing radiological procedures involving the mesenteric vessels should keep in mind, the variations in the branching pattern of the mesenteric vessels. Knowledge of this rare anatomical variant of left colic artery is of significant clinical importance in pancreatic surgeries such as Whipple procedure for treatment of pancreatic carcinomas, in vascular studies \& radiological interventional procedures such as Transcatheter Arterial Embolization in treatment of ruptured left colic artery aneurysm.

\section{REFERENCES}

[1] Standring, S. (2005) Gray's anatomy. 39th Edition, El- sevier Churchill Livingstone, Edinburgh, 1360-1365.

[2] Yeo, C.J., Cameron, J. L., Sohn, T.A., et al. (1997) Six hundred fifty consecutive pancreaticoduodenectomy in the 1990s: Pathology, complications, and outcomes. Annals of Surgery, 226, 248-257. http://dx.doi.org/10.1097/00000658-199709000-00004

[3] Stojadinovic, A., Brooks, A., Hoos, A., et al. (2003) An evidence-based approach to the surgical management of resectable pancreatic adenocarcinoma. Journal of the American College of Surgeons, 196, 954-964. http://dx.doi.org/10.1016/S1072-7515(03)00010-3

[4] Buchler, M.W., Wagner, M., Schmied, B.M., et al. (2003) Changes in mortality after pancreatic resection: towards the end of completion pancreatectomy. Archives of Surgery, 138, 1310-1314. http://dx.doi.org/10.1001/archsurg.138.12.1310

[5] Strasberg, S.M., Drebin, J.A. and Soper, N.J. (1997) Evolution and current status of the Whipple procedure: An update for gastroenterologists. Gastroenterology, 113, 983994. http://dx.doi.org/10.1016/S0016-5085(97)70195-1

[6] Suc, B., Msika, S., Piccinini, M., et al. (2004) Octreotide in the prevention of intra-abdominal complications following elective pancreatic resection: A prospective, multicenter randomized controlled trial. Archives of Surgery, 139, 288-294.

http://dx.doi.org/10.1001/archsurg.139.3.288

[7] Adam, U., Makowiec, F., Riediger, H., et al. (2004) Risk factors for complications after pancreatic head resection. American Journal of Surgery, 187, 201-208. http://dx.doi.org/10.1016/j.amjsurg.2003.11.004

[8] Datta, A.K. (2005) Essentials of human embryology. 5th Edition, Current Books International, Kolkata, 192-193.

[9] Amonoo-Kuofi, H.S., El-Badawi, M.G. and El-Naggar, M.E. (1995) Anomalous origins of colic arteries. Clinical Anatomy, 8, 288-293. http://dx.doi.org/10.1002/ca.980080408

[10] Kardile, P.B., Ughade, J.M., Ughade, M.N., et al. (2013) Anomalous origin of the hepatic artery from the heaptomesenteric trunk. Journal of Clinical and Diagnostic Research, 7, 386-388.

[11] Ashwini, H., Sandhya, K., Archana, H., et al. (2013) Branching pattern of the colic branches of superior mesenteric artery-A cadaveric study. International Journal of Biological and Medical Research, 4, 3004-3006.

[12] Dahiphale, V., Selukar, M. and Promod, R.K. (2013) Variations in branching pattern of superior mesenteric artery. International Journal of Recent Trends in Science and Technology, 5, 166-167.

[13] Simeon, S., Philip, M., Johnstone, M., et al. (2013) Branching Pattern of inferior mesenteric artery in a black african population: A dissection study. ISRN Anatomy, 2013, Article ID: 962904. http://dx.doi.org/10.5402/2013/962904

[14] Rusu, M.C., Vlad, M., Voinea, L.M., et al. (2008) Detailed anatomy of a left accessory aberrant colic artery. Surgical and Radiologic Anatomy, 30, 595-599. http://dx.doi.org/10.1007/s00276-008-0362-1

[15] Hideki, K., Koichiro, I. and Tatsuo, S. (2007) A case of celiacomesenteric trunk with some other arterial anoma- 
lies in a Japanese woman. Anatomical Science International, 82, 53-58.

http://dx.doi.org/10.1111/j.1447-073X.2006.00156.x

[16] Kim, D.H., Jin, C., Jung, Y.W., et al. (2009) The accessory left colic artery arising from the superior mesenteric artery: A case report. Korean Journal of Anatomy, 42, 209212.
[17] Jiji, P.J., Nayak, S.R., D’Costa, S., et al. (2008) A variant of Buhler's arc formed by the unusually long dorsal pancreatic artery. Bratislavske Lekarske Listy, 109, 288-289.

[18] Langman, J. (1985) Medical embryology. 5th Edition, Williams and Wilkins, Baltimore, 230-246. 